\title{
Farinha de Varredura de Mandioca (Manihot esculenta) na Alimentação de Alevinos de Tilápia do Nilo (Oreochromis niloticus L.)
}

\author{
Wilson Rogério Boscolo ${ }^{1}$, Carmino Hayashi², Fábio Meurer ${ }^{3}$
}

\begin{abstract}
RESUMO - Objetivando avaliar a utilização de diferentes níveis de inclusão de farinha de varredura de mandioca $(0,00 ; 6,00 ; 12,00$; 18,00 e 24,00\%) em rações com 30,00\% de proteína digestível e $3000 \mathrm{kcal} / \mathrm{kg}$ de energia digestível para alevinos de tilápia do Nilo, foi realizado um experimento no Laboratório de Aqüicultura/DBI/UEM, utilizando-se 200 alevinos revertidos de tilápia do Nilo da linhagem tailandesa, com peso médio de $0,84 \mathrm{~g}$ e 35 dias de idade, distribuídos em 25 tanques de $250 \mathrm{~L}$, num delineamento inteiramente casualisado com cinco tratamentos e cinco repetições. Foram avaliadas as médias de ganho de peso (GP), conversão alimentar aparente (CAa), sobrevivência (S), índice hepato-somático (IHS), rendimento de carcaça (RC) e porcentagem de gordura na carcaça (GC). O GP, CAa, $\mathrm{S}$, IHS e RC não apresentaram diferenças entre os tratamentos. O GC apresentou redução linear com o aumento nos níveis de inclusão de farinha de varredura de mandioca $\left(Y=12,22-0,08657 \mathrm{X} ; \mathrm{r}^{2}=0,77\right)$. Concluiu-se que a farinha de varredura de mandioca pode ser utilizada na alimentação de alevinos de tilápia do Nilo até o nível de $24 \%$ de inclusão, substituindo toda a energia do milho, sem causar prejuízos no desempenho dos animais.
\end{abstract}

Palavras-chave: desempenho, farinha de varredura de mandioca, Manihot esculenta, Oreochromis niloticus, tilápia do Nilo

\section{Cassava by-Product Meal (Manihot esculenta) on Feeding of Nile Tilapia (Oreochromis niloticus L.) Fingerlings}

\begin{abstract}
Aiming to evaluate different inclusion levels of cassava meal $(0.00,6.00,12.00,18.00$ and $24.00 \%)$ in diets with $30.00 \%$ of digestible protein and $3,000 \mathrm{kcal} / \mathrm{kg}$ of digestible energy to Nile tilapia fingerlings, an experiment was carried out at the Aquaculture Laboratory /DBI/UEM. Two hundred reverted Thai strain Nile tilapia fingerlings were utilized, with an initial weight of $0.84 \mathrm{~g}$ and 35 days old, distributed in $25250 \mathrm{~L}$ tanks, in a completely randomized design with five treatments and five replications. Averages of weight gain (GP), apparent feed conversion (CAa), survival (S), hepatic-somatic rate (IHS), carcass yield (RC) and fat carcass percentage (GC) were evaluated. The GP, CAa, S, IHS and RC did not shew differences among treatments. GC linear decrease with an increase inclusion levels cassava meal diets $\left(\mathrm{Y}=12.22-0.08657 \mathrm{X} ; \mathrm{r}^{2}=0.77\right)$. It was concluded that cassava meal may be used in the Nile tilapia fingerlings feeding up to $24 \%$ inclusion level, whole replaced the energy of corn without decrease on performance.
\end{abstract}

Key Words: cassava by-product meal, Manihot esculenta, Nile tilapia, Oreochromis niloticus, performance

\section{Introdução}

A tilápia é a segunda espécie de maior importância na aqüicultura mundial (Alceste \& Jory, 1998; Lovshin, 1998). A tilápia do Nilo é de baixo nível trófico (onívora) fato este que a coloca em vantagem em relação as espécies carnívoras que requerem grande quantidade de farinha de peixe nas rações (Fitzsimmons, 2000), com boa aceitação no mercado consumidor, destacando-se em cultivos, por apresentar crescimento rápido, rusticidade (Hayashi et al., 1999), carne de ótima qualidade, e por não apresentarem espinhos na forma de "Y" no seu filé (Hildsorf,
1995), sendo apropriada para a filetagem, tornandoa uma espécie de grande interesse para a piscicultura. No Brasil, outro segmento responsável por um grande incremento da produção de peixes é o sistema de "pesque-pague", que nos últimos anos ampliou em muito a sua demanda (Borghetti \& Ostrensky, 1998). Estas características contribuem para o aumento verificado na produção mundial da espécie (Boscolo et al., 1999).

A mandioca (Manihot esculenta) é um alimento comum em países tropicais e semitropicais, sendo conhecida por vários nomes, como cassava, tapioca, manioc, manihot, entre outros (Viola et al., 1988). É

\footnotetext{
${ }^{1}$ Professor MSc. do Curso de Engenharia de Pesca/UNIOESTE-Toledo-PR, Programa de Pós-Graduação em Zootecnia/Universidade Estadual de Maringá. Av. Colombo, 5790, Jardim Universitário, Maringá - Paraná. E.mail: wrboscolo@bol.com.br

2 Professor Titular do Depto. de Biologia/UEM. E.mail: chayashi@uem.br

${ }^{3}$ Zootecnista Msc, Pós-graduando do Programa de Pós-Graduação em Zootecnia/Universidade Estadual de Maringá. E.mail: f-meurer@bol.com.br
} 
uma planta nativa do Brasil, cultivada praticamente em todo o seu território (Gomes \& Peña, 1997), tem um alto potencial para a alimentação animal, é uma fonte rica em energia, seus diferentes resíduos (casca de mandioca, farinha de varredura, entre outros) podem ser utilizados na alimentação animal (Martins et al., 2000). A farinha de mandioca é rica em amido, e este nutriente é utilizado eficientemente, em relação a outras espécies de peixe, pela tilápia do Nilo (Viola \& Arieli, 1983; Anderson et al., 1984; Degani \& Revach, 1991; Shiau, 1997), apresentando portanto um considerável valor energético (Viola et al., 1988). A farinha de varredura de mandioca é a farinha de mandioca destinada ao consumo humano que por algum motivo cai no chão da fábrica, sendo portanto um subproduto do processamento da mandioca pelas indústrias farinheiras e apresenta boa disponibilidade a baixo custo na região noroeste do Paraná.

A farinha de mandioca apresenta um efeito aglutinante, característica esta favorável a formulação de rações aqüícolas, diminuindo a dissolução desta na água e conseqüente perda de nutrientes, propiciando um melhor aproveitamento pelo animal (Seixas et al., $1997 \mathrm{ab}$ ).

Eusebio \& Coloso (1998) avaliando a inclusão de $13 \%$ de farinha de mandioca em dietas para o camarão Penaeus indicus não observaram prejuízo no desempenho dos animais.

Viola et al. (1988), avaliando a utilização de mandioca na alimentação de tilápias híbridas (O. aureus $X O$. niloticus) na fase de terminação $(250-400 \mathrm{~g})$, recebendo ração contendo $30 \%$ de inclusão de mandioca em substituição ao sorgo, não observaram diferença no desempenho dos animais. Resultados semelhantes foram observados pelos mesmos autores com carpas alimentadas com níveis de 20 e $40 \%$ de inclusão.

Sahle et al. (1992) demonstraram que a farinha de mandioca pode ser incluída em até $45 \%$ em rações para gansos sem prejudicar o desempenho dos animais. Resultados semelhantes foram obtidos por Patterson et al. (1994), avaliando o desempenho de frangos de corte com $20 \%$ de inclusão de farinha de mandioca na ração.

O presente trabalho teve por objetivo avaliar o efeito de diferentes níveis de inclusão da farinha de varredura de mandioca (Manihot esculenta), substituindo toda energia do milho, em rações para alevinos revertidos de tilápia do Nilo (O. niloticus).

\section{Material e Métodos}

O experimento foi realizado no Laboratório de Aqüicultura/DBI da Universidade Estadual de Maringá por um período de 42 dias, de abril a maio de 2000 .

Foram utilizados 200 alevinos revertidos de tilápia do Nilo, da linhagem tailandesa, com peso médio de 0,84 g e 35 dias de idade, distribuídos em 25 tanques de $250 \mathrm{~L}$, em um delineamento inteiramente casualisado com cinco tratamentos e cinco repetições, sendo a unidade experimental constituída por um tanque de 250 litros com oito peixes. Os tanques foram equipados com sistema de aeração constante por meio de um compressor de ar e aquecidos por aquecedores de $100 \mathrm{~W}$. O sistema de entrada e saída de água era individual, com renovação de $20 \%$ do volume total por dia.

As rações foram fornecidas quatro vezes ao dia às $9 \mathrm{~h}, 11 \mathrm{~h} 30,14 \mathrm{~h}$ e $17 \mathrm{~h}$, na proporção de $10 \%$ do peso vivo. A quantidade de ração fornecida foi corrigida diariamente, isto é, aumentou-se $10 \%$ do peso da ração fornecida no dia anterior. Todos os peixes de cada unidade experimental foram pesados a cada 10 dias para aferir a quantidade de ração fornecida. Diariamente, no período da manhã os tanques foram sifonados para a retirada das fezes depositadas no fundo das caixas.

As rações experimentais foram formuladas com níveis de 0,$00 ; 6,00 ; 12,00 ; 18,00$ e 24,00\% de inclusão de farinha de varredura de mandioca (Tabela 1), de acordo com as exigências para a espécie conforme NRC (1993) e com base nos valores digestíveis obtidos por Boscolo (2001), sendo as mesmas isocalóricas, isocálcicas, isofosfóricas e isoprotéicas e isoaminoacídicas para metionina mais cistina e lisina (Tabela 2).

Para a elaboração das dietas experimentais, os alimentos foram processados individualmente em um moinho tipo faca com peneira de $0,5 \mathrm{~mm}$, após foram misturados e umedecidos com água a $50^{\circ} \mathrm{C}$ para serem peletizados e secos em estufa a $55^{\circ} \mathrm{C}$ por 12 horas. Para o fornecimento aos animais, as rações foram desintegradas e peneiradas de modo a apresentarem granulometrias que melhor se adaptem ao tamanho da boca dos animais.

Os parâmetros da água $\mathrm{pH}$ e oxigênio dissolvido $(\mathrm{mg} / \mathrm{L})$ foram medidos semanalmente, enquanto a temperatura $\left({ }^{\circ} \mathrm{C}\right)$ foi tomada diariamente de manhã (8h) e à tarde (16h30). 
Tabela 1 - Composição percentual das rações experimentais com diferentes níveis de inclusão de farinha de varredura de mandioca, utilizadas para alevinos de tilápia do Nilo (matéria natural) ${ }^{1}$

Table 1 - Percentage composition of the experimental rations with different cassava by-product meal inclusion levels, used for Nile tilapia fingerlings (as fed basis)

\begin{tabular}{|c|c|c|c|c|c|}
\hline \multirow[t]{2}{*}{$\begin{array}{l}\text { Alimentos (\%) } \\
\text { Foods (\%) }\end{array}$} & \multicolumn{5}{|c|}{$\begin{array}{c}\text { Níveis de inclusão (\%) } \\
\text { Inclusion levels (\%) }\end{array}$} \\
\hline & 0 & 6 & 12 & 18 & 24 \\
\hline $\begin{array}{l}\text { Milho } \\
\text { Corn }\end{array}$ & 26,17 & 19,61 & 13,06 & 6,50 & 0,00 \\
\hline $\begin{array}{l}\text { Farinha de varredura } \\
\text { de mandioca }\end{array}$ & 0,00 & 6,00 & 12,00 & 18,00 & 24,00 \\
\hline $\begin{array}{l}\text { Cassava by-product meal } \\
\text { Farelo de soja }\end{array}$ & 66,65 & 67,52 & 68,39 & 69,26 & 70,12 \\
\hline Soybean meal & & & & & \\
\hline $\begin{array}{l}\text { Calcário calcítico } \\
\text { Limestone }\end{array}$ & 1,58 & 1,56 & 1,53 & 1,51 & 1,45 \\
\hline $\begin{array}{l}\text { Fosfato bicálcico } \\
\text { Dicalciumphosphat }\end{array}$ & 2,54 & 2,55 & 2,55 & 2,56 & 2,56 \\
\hline $\begin{array}{l}\text { Óleo de soja } \\
\text { Soybean oil }\end{array}$ & 1,94 & 1,66 & 1,38 & 1,10 & 0,80 \\
\hline $\begin{array}{l}\text { L-lisina } \\
\text { L-lysine }\end{array}$ & 0,08 & 0,06 & 0,04 & 0,02 & 0,00 \\
\hline $\begin{array}{l}\text { Suplemento min. vitam. } \\
\text { Mineral and vitamin } \\
\text { supplement }\end{array}$ & 0,50 & 0,50 & 0,50 & 0,50 & 0,50 \\
\hline $\begin{array}{l}\text { Antioxidante }(\mathrm{BHT}) \\
\text { Antioxidant }(B H T)\end{array}$ & 0,02 & 0,02 & 0,02 & 0,02 & 0,02 \\
\hline $\begin{array}{l}\text { Aglutinante (Alginato) } \\
\text { Binders (Alginate) }\end{array}$ & 0,02 & 0,02 & 0,02 & 0,02 & 0,02 \\
\hline $\begin{array}{l}\text { Salcomum } \\
\text { Salt }\end{array}$ & 0,50 & 0,50 & 0,50 & 0,50 & 0,50 \\
\hline Total & 100,00 & 100,00 & 100,00 & 100,00 & 100,00 \\
\hline
\end{tabular}

${ }^{1}$ Baseados nos valores de composição dos alimentos calcário e fosfato bicálcico (Rostagno et al., 1994); bagaço de cana, milho, farelo de soja e farinha de varredura de mandioca (LANA-DZO/UEM) (Based on the values of composition of foods calcium and dicalcium phosphate [Rostagno et al., 1994]; sugarcane bagasse, corn, soybean meal and cassava meal (LANA-DZO/UEM)).

${ }^{2}$ Níveis de garantia por quilograma do produto (Supremais) (Guarantee levels per kilogram of product): Vit. A, 1.200.000 UI; Vit. $\mathrm{D}_{3}, 200.000 \mathrm{UI}$; Vit. E, $12.000 \mathrm{mg}$; Vit. K3, $2.400 \mathrm{mg}$; Vit. B1, $4.800 \mathrm{mg}$; Vit. B2, 4.800 mg; Vit. B6, $4.000 \mathrm{mg}$; Vit. B12, 4.800 $\mathrm{mg}$; Ác. fólico (Folic acid), $1.200 \mathrm{mg}$; Pantotenato de cácio, (calcium pantotenate) $12.000 \mathrm{mg}$; Vit. C, $48.000 \mathrm{mg}$; Biotina (Biotin), $48 \mathrm{mg}$; Colina (Colin), 65.000 mg; Niacina (Niacin), $24.000 \mathrm{mg}$; Fe (Iron), $10.000 \mathrm{mg} ; \mathrm{Cu}, 6.000 \mathrm{mg}$; Mn, $4.000 \mathrm{mg} ; \mathrm{Zn}, 6.000 \mathrm{mg}$; I, 20 mg; Co, 2 mg; Se, 20 mg.

Ao final do período experimental, foram efetuadas as medidas individuais de peso $(\mathrm{g})$ e comprimento total $(\mathrm{cm})$ dos peixes de cada unidade experimental. As variáveis avaliadas foram: ganho de peso diário (g), conversão alimentar aparente, sobrevivência, rendimento de carcaça e porcentagem de gordura.

Para análise de percentagem de gordura as carcaças (peixes sem cabeça e eviscerados) de cada unidade experimental foram secas em estufa de ven-
Tabela 2 - Composição química das rações experimentais com diferentes níveis de inclusão de farinha de varredura de mandioca, utilizadas para alevinos de tilápia do Nilo ${ }^{1}$

Table 2 - Chemical composition of experimental rations with different cassava by-product meal inclusion levels, used for Nile tilapia fingerlings

\begin{tabular}{|c|c|c|c|c|c|}
\hline $\begin{array}{l}\text { Nutrientes (\%) } \\
\text { Nutrients (\%) }\end{array}$ & & $\begin{array}{r}\text { Valor } \\
\text { Calc }\end{array}$ & $\begin{array}{l}\text { es calcul } \\
\text { ulated va }\end{array}$ & $\begin{array}{l}\text { ados } \\
\text { ues }\end{array}$ & \\
\hline $\begin{array}{l}\text { Energia digestível }{ }^{2} 3 \\
(\mathrm{kcal} / \mathrm{kg}) \\
\text { Digestible energy }\end{array}$ & 3000,00 & 3000,00 & 3000,00 & 3000,00 & 3000,00 \\
\hline $\begin{array}{l}\text { Proteína digestível } \\
(\mathrm{kcal} / \mathrm{kg})\end{array}$ & 30,00 & 30,00 & 30,00 & 30,00 & 30,00 \\
\hline $\begin{array}{l}\text { Digestible protein } \\
\text { Cálcio }\end{array}$ & 0,74 & 0,74 & 0,74 & 0,74 & 0,74 \\
\hline $\begin{array}{l}\text { Calcium } \\
\text { Fósforo disponível } \\
\text { Available phosphorus }\end{array}$ & 0,60 & 0,60 & 0,60 & 0,60 & 0,60 \\
\hline $\begin{array}{l}\text { Extrato etéreo } \\
\text { Ether extract }\end{array}$ & 4,60 & 4,12 & 3,64 & 3,15 & 2,65 \\
\hline & 1,78 & 1,51 & 1,25 & 0,98 & 0,71 \\
\hline $\begin{array}{l}\text { Fibra bruta } \\
\text { Crude fiber }\end{array}$ & 3,76 & 3,86 & 3,96 & 4,06 & 4,16 \\
\hline $\begin{array}{l}\text { Metionina }+ \text { Cistina } \\
\text { Methionine }+ \text { Cystine }\end{array}$ & 1,09 & 1,09 & 1,09 & 1,09 & 1,09 \\
\hline $\begin{array}{l}\text { Lisina } \\
\text { Lysine }\end{array}$ & 2,03 & 2,03 & 2,03 & 2,03 & 2,03 \\
\hline
\end{tabular}

${ }^{1}$ Exigência nutricional baseada no NRC (1993).

${ }^{2}$ Baseados nos valores de energia digestível para tilápia do Nilo propostos para: milho $3.037,63 \mathrm{kcal} / \mathrm{kg}$; farelo de soja $3057,63 \mathrm{kcal} / \mathrm{kg}$; farinha de varredura de mandioca 3280,09 kcal/kg; e óleo de soja $8.485,28 \mathrm{kcal} / \mathrm{kg}$ (Boscolo, 2001).

${ }^{3}$ Baseados nos valores de proteína digestível para tilápia do Nilo propostos para: milho 7,18; farelo de soja 42,19 ; e milheto de $13,88 \%$ (Boscolo, 2001).

${ }^{1}$ Nutritional requiremennt of NRC (1993).

${ }^{2}$ Based on the values of digestible protein for Nile tilapia proposed for corn: 7.18; for soybean meal: 42.19 and for millet pearls of $13.88 \%$ (Boscolo, 2001).

${ }^{3}$ Based on the values of digestible energy for Nile tilapia proposed for corn: $3,037.63 \mathrm{kcal} / \mathrm{kg}$; for soybean meal: 3,057.63 kcal/kg; for cassava meal: 3,280.09 kcal/kg; for soybean oil: 8,485.28 kcal/kg Boscolo (2001).

tilação $55^{\circ} \mathrm{C}$ por 72 horas; posteriormente as carcaças foram moídas em moinho tipo bola e analisadas conforme Silva (1990).

Os dados obtidos ao final do experimento foram submetidos à análise de variância em nível de $5 \%$ de probabilidade e em caso de diferenças aplicou-se análise de regressão através do programa estatístico SAEG (Sistema de Análise Estatística e Genética) descrito por Euclydes (1983). 


\section{Resultados e Discussão}

Os valores médios de temperatura, oxigênio dissolvido e $\mathrm{pH}$ durante o período experimental foram de $26,52 \pm 2,07^{\circ} \mathrm{C} ; 5,17 \pm 0,61 \mathrm{mg} / \mathrm{L}$ e $7,60 \pm 0,23$, respectivamente, permanecendo dentro da faixa recomendada para a aqüicultura (Boyd, 1990; Sipaúba-Tavares, 1995).

Os valores médios de desempenho de alevinos de tilápias do Nilo ao final do período experimental estão apresentados na Tabela 3.

O ganho de peso dos animais não foi influenciado $(\mathrm{P}>0,05)$ pelos diferentes tratamentos durante o período experimental.

Gallego et al. (1994), avaliando a utilização de amido de trigo, malto-dextrina de milho, farinha de mandioca, e amido de milho pré-gelatinizado, na alimentação da enguia européia (Anguilla anguilla), observaram que a farinha de mandioca é bem aproveitada por esta espécie, promovendo taxas de crescimento superiores ao amido de milho pré-gelatinizado e similar às outras fontes de carboidratos avaliadas.

A farinha de mandioca apresenta características aglutinantes como observado por Seixas et al. (1997b), estes autores avaliando a farinha de mandioca como aglutinante em dietas para pós larvas de camarão Macrobrachium rosenbergii, observaram melhor ganho de peso dos animais alimentados com rações contendo este alimento do que quando comparados com outros aglutinantes como farinha de trigo, melaço seco e um aglutinante comercial. Este melhor desempenho observado pelos autores pode ser devido à menor lixiviação dos nutrientes da ração contendo a farinha de mandioca. No entanto, no presente experimento, não foi observado tal efeito, principalmente pelo fato de que os diferentes tratamentos não afetaram a conversão alimentar dos animais.

$\mathrm{O}$ aumento na inclusão de farinha de varredura de mandioca nas rações não influenciou a conversão alimentar dos animais, demonstrando que este alimento não apresenta problemas quanto a aceitabilidade pela tilápia do Nilo e que a sua inclusão não implicou em desbalanço nutricional das rações avaliadas, visto que foram formuladas com base em nutrientes digestíveis.

A sobrevivência dos animais não foi influenciada pelos diferentes níveis de inclusão da farinha de varredura de mandioca. O ácido hidrociânico é um composto tóxico presente em algumas variedades de mandioca in natura, no entanto este composto é termolábil, sendo inativado durante o processamento (Viola et al., 1988), sendo, portanto, este alimento isento de fatores prejudiciais à saúde dos animais.

O rendimento de carcaça e o índice hepatosomático não foram afetados pelos diferentes níveis de inclusão da farinha de varredura de mandioca. Por outro lado, a percentagem de gordura na carcaça reduziu linearmente $(\mathrm{P}<0,05)$, segundo a equação $\left(\mathrm{Y}=12,22-0,08657 \mathrm{X} ; \mathrm{r}^{2}=0,77\right)$ com o aumento nos níveis de inclusão da farinha de varredura de mandioca (Tabela 4). Estes resultados discordam dos resultados obtidos por Viola et al. (1988) que não observaram diferenças na percentagem de gordura na carcaça da tilápia e da carpa na fase de terminação.

A diminuição na percentagem de gordura na carcaça observada no presente experimento (Figura 1) provavelmente ocorreu devido à menor inclusão de óleo vegetal com o aumento nos níveis de inclusão de FM. Este resultado também foi observado por De Silva et al. (1991), El-Sayed \& Teshima (1992) e Meurer et al. (1999), em trabalhos onde houve variação nos níveis lipídicos ou de energia em rações para tilápias.

Tabela 3 - Desempenho de alevinos de tilápia do Nilo alimentadas com diferentes níveis de inclusão de farinha de varredura de mandioca

Table 3 - Performance of Nile tilapia fingerlings fed diet with different cassava by-product meal inclusion levels

\begin{tabular}{|c|c|c|c|c|c|c|}
\hline \multirow[t]{2}{*}{$\begin{array}{l}\text { Parâmetros } \\
\text { Parameters }\end{array}$} & \multicolumn{5}{|c|}{$\begin{array}{l}\text { Níveis de inclusão de farinha de varredura (\%) } \\
\text { Cassava by-product meal inclusion levels }\end{array}$} & \multirow[b]{2}{*}{$\mathrm{CV}(\%)$} \\
\hline & 0 & 6 & 12 & 18 & 24 & \\
\hline $\begin{array}{l}\text { Peso inicial }(\mathrm{g}) \\
\text { Initial weight }(g)\end{array}$ & 0,85 & 0,84 & 0,83 & 0,86 & 0,85 & 2,68 \\
\hline $\begin{array}{l}\text { Ganho de peso (g) } \\
\text { Weight gain }(g)\end{array}$ & 8,52 & 8,33 & 7,34 & 8,73 & 8,25 & 14,83 \\
\hline $\begin{array}{l}\text { Conversão alimentar } \\
\text { Feed:gain ratio }\end{array}$ & 1,58 & 1,67 & 1,75 & 1,50 & 1,60 & 15,75 \\
\hline $\begin{array}{l}\text { Sobrevivência }(\%) \\
\text { Survival rate }(\%)\end{array}$ & 100,00 & 95,00 & 90,00 & 95,00 & 97,50 & 7,17 \\
\hline
\end{tabular}


Tabela 4 - Características de carcaça de alevinos de tilápia do Nilo alimentadas com diferentes níveis de inclusão de farinha de varredura de mandioca

Table 4 - Carcass characteristics of Nile tilapia fingerlings fed diets with different cassava by-product meal inclusion levels

\begin{tabular}{|c|c|c|c|c|c|c|}
\hline \multirow[t]{2}{*}{$\begin{array}{l}\text { Parâmetros } \\
\text { Parameters }\end{array}$} & \multicolumn{5}{|c|}{$\begin{array}{l}\text { Níveis de inclusão de farinha de varredura (\%) } \\
\text { Cassava by-product meal inclusion levels }\end{array}$} & \multirow[b]{2}{*}{$\mathrm{CV}(\%)$} \\
\hline & 0 & 6 & 12 & 18 & 24 & \\
\hline $\begin{array}{l}\text { İndice hepato-somático } \\
\text { Hepatic-somatic rate }\end{array}$ & 1,70 & 1,85 & 1,77 & 1,86 & 1,95 & 21,36 \\
\hline $\begin{array}{l}\text { Rendimento de carcaça (\%) } \\
\text { Carcass yield (\%) }\end{array}$ & 86,85 & 86,58 & 85,41 & 86,79 & 87,63 & 1,94 \\
\hline $\begin{array}{l}\text { Gordura na carcaça } \mathrm{MS}(\%)^{1} \\
\text { Fat in carcass dry matter (\%) }\end{array}$ & 12,08 & 11,94 & 10,80 & 11,28 & 9,81 & 1,84 \\
\hline
\end{tabular}

${ }^{1}$ Efeito linear $\left(Y=12,22-0,08657 X ; r^{2}=0,77\right)$

${ }^{1}$ Linear effect $\left(Y=12.22-0.08657 X ; r^{2}=0.77\right)$

Resultados semelhantes aos determinados no presente trabalho foram obtidos por Patterson et al. (1994), avaliando o desempenho de frangos de corte, e Sahle et al.(1992), avaliando o desempenho de gansos alimentados com rações contendo farinha de mandioca, em que se constatou a possibilidade de inclusão deste alimento sem prejudicar o desempenho destes animais.

Os resultados de desempenho obtidos no presente experimento estão de acordo com Viola \& Arieli (1983), Anderson et al. (1984), Degani \& Revach (1991) e Shiau (1997), os quais relataram que o amido é um nutriente utilizado eficientemente pela tilápia do Nilo.

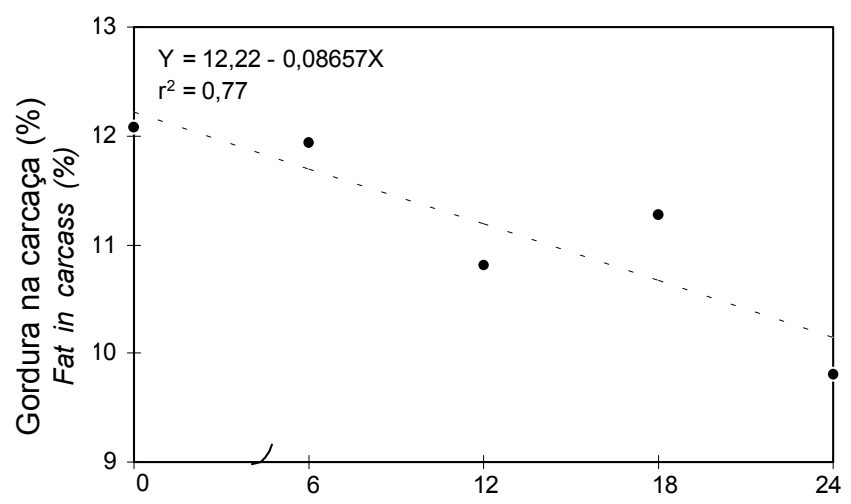

Inclusão de farinha de varredyra de mandioca (\%) Cassava by-product meal inclusion level (\%)

Figura 1 - Porcentagem de gordura na carcaça de alevinos de tilápia do Nilo alimentadas com diferentes níveis de inclusão de farinha de varredura de mandioca.

Figure 1 - Carcass percent fat of Nile tilapia fingerlings fed diet with different cassava by-product meal inclusion levels.

\section{Conclusões}

A farinha de varredura de mandioca (Manihot esculenta) pode ser incluída na ração para alevinos de tilápia do Nilo (O. niloticus) até o nível de $24 \%$, substituindo toda a energia fornecida pelo milho, sem redução no desempenho dos animais.

\section{Literatura Citada}

ALCESTE, C.; JORY, D.E. Análisis de las tendencias actuales en la comercialización de tilapia en los Estados Unidos de Norteamérica y la Unión Europea. In: CONGRESSO SULAMERICANO DE AQÜICULTURA, 1., 1998, Recife. Anais... Recife: SIMBRAq, 1998. p.349-364.

ANDERSON, J. JACKSON, A.J., MATTY, A.J. et al. Effects of dietary carbohydrates and fiber on the tilapia, Oreochromis niloticus (Linn.). Aquaculture, v.13, p.265-272, 1984.

BORGHETTI, J.R.; OSTRENSKY, A. Estratégias e ações governamentais para incentivar o crescimento da atividade aquicola no Brasil. In: CONGRESSO SUL-AMERICANO DE AQÜICULTURA, 1., 1998, Recife. Anais... Recife: SIMBRAq, 1998. p.437-447.

BOSCOLO, W.R. Avaliação de alimentos convencionais e alternativos para tilápias do Nilo. Maringá, PR: Universidade Estadual de Maringá, 2001. 78p. Dissertação (Mestrado em Zootecnia) - Universidade Estadual de Maringá, 2001.

BOSCOLO, W.R.; HAYASHI, C.; SOARES, C.M. et al. Desempenho de machos revertidos de tilápia do Nilo (Oreochromis niloticus, L.), linhagens tailandesa e comum nas fases inicial e de crescimento. In: ACUICULTURA VENEZUELA, 1999, Puerto La Cruz, Venezuela. Anais... Puerto La Cruz, Venezuela: ASA, 1999. p.84-91.

BOYD, C. Water quality in ponds for aquaculture. London: Birmingham Publishing Co., 1990. 482p.

DEGANI, G.; REVACH, A. Digestive capabilities of three commensal fish species: carp, Cyprinus carpio L., tilapia, Oreochromis aureus $X$ O. niloticus, and African catfish, Clarias gariepinus (Burchel 1822). Aquaculture Fish Managment, v.22, p.397-403, 1991. 
DESILVA, S.S.; GUNASEKERA, R.M.; SHIM, K.F. Interactions of varying dietary-protein and lipid-levels in young red tilapia- evidence of protein sparing. Aquaculture, v.95, n.3-4, p.305-318, 1992.

EL-SAYED, A.F.M.; TESHIMA. S. Protein and energyrequirements of Nile tilapia, Oreochromis niloticus, Fry. Aquaculture, v.103, n.1, p.55-63, 1992.

EUCLIDES, R.F. Manual de utilização do programa SAEG (Sistema para Análises Estatística e Genética). Viçosa, MG: Universidade Federal de Viçosa, 1983. 59p.

EUSEBIO, P.S.; COLOSO, R.M. Evaluation of leguminous seed meals and leaf meals as plant protein sources in diets for juvenile Peneaus indicus. The Israeli Journal of Aquaculture, v.50, n.2, p.47-54, 1998.

FITZSIMMONS, K. Tilapia: most important aquaculture species of the $21^{\text {st }}$ century. In: PROCEEDINGS FROM THE FIFTH INTERNATIONAL SYMPOSIUM ON TILAPIA AQUACULTURE, 2000, Rio de Janeiro. Anais... Rio de Janeiro, 2000. p.3-8.

GALLEGO, M.G.; BAZOCO, J.; AKHARBACH, H. et al. Utilization of different carbohydrates by the european eel (ANGUILlA-ANGUILlA). Aquaculture, v.124, n.1-4, p.99-108, 1994.

GOMES, S.Z.; PEÑA, M.C.G. Digestibilidade aparente da mandioca (Manioc esculenta) pelo camarão de água doce (Macrobrachium rosenbergii). Revista Brasileira de Zootecnia, v.26, n.5, p.858-862, 1997.

HAYASHI, C.; BOSCOLO, W.R.; SOARES, C.M. et al. Uso de diferentes graus de moagem dos ingredientes em dietas para a tilápia do Nilo (Oreochromis niloticus L.) na fase de crescimento. Acta Science, v.21, n.3, p.733-737, 1999

HILDSORF, A.W.S. Genética e cultivo de tilápias vermelhas, uma revisão. Boletim Instituto de Pesca, v.22, n.1, p.73-78, 1995.

LOVSHIN, L.L. Red tilapia or Nile tilapia: which is the best culture fish? In: SIMPÓSIO SOBRE MANEJO E NUTRIÇÃO DE PEIXES, 1998, Piracicaba. Anais... Piracicaba: Colégio Brasileiro de Nutrição Animal, 1998. p.179-198.

MARTINS, A.S.; PRADO, I.N.; ZEOLA, L.M. et al. Digestibilidade aparente de dietas contendo milho ou casca de mandioca como fonte energética e farelo de algodão ou levedura como fonte protéica em novilhas. Revista Brasileira de Zootecnia, v.29, n.1, p.269-277, 2000.

MEURER, F.; HAYASHI, C.; SOARES, C.M. et al. Níveis de gordura na alimentação de machos de tilápia do Nilo (Oreochromis niloticus, L.), revertidos sexualmente, na fase inicial. In: ACUICULTURA VENEZUELA, 1999, Puerto La Cruz, Venezuela. Anais... Puerto La Cruz, Venezuela: ASA, 1999. p.348-357.
NATIONAL RESEARCH COUNCIL - NRC. Nutrient requirements of warmwater, fishes and shellfishes: nutrient requirements of domestics animals. Washington, D.C.: 1993. 114p.

PATTERSON, P.H.; ACAR, N.; COLEMAN, W.C. Feeding value of poultry by-products extruded with cassava, barley, and wheat middling for broiler chicks - The effect of ensiling poultry by-products as a preservation method prior to extrusion. Poultry Science, v.73, n.7, p.1107-1115, 1994.

ROSTAGnO, H.S.; SILVA, D.J.; COSTA, P.M.A. Composição de alimentos e exigências nutricionais de aves e suínos (Tabelas brasileiras). Viçosa, MG: Universidade Federal de Viçosa, 1994. 54p.

SAHLE, M.; COLEOU, J.; HAAS, C. Nutritional value of cassava meal in diets for geese. Animal Feed Science and Technology, v.36, n.1-2, p.19-40, 1992.

SEIXAS, J.T.E., ROSTAGNO, H.S., EUCLYDES, R.F. et al. Efeito de aglutinantes na hidrosolubilidade de dietas balanceadas para o camarão de água doce (Macrobachium roserbergii de Man) no estágio pós-larva. Revista Brasileira de Zootecnia, v.26, n.4, p.629-637, 1997a.

SEIXAS, J.T.E.; ROSTAGNO, H.S.; QUEIROZ, A.C. et al. Avaliação do desempenho de pós-larvas de camarão de água doce (Macrobachium roserbergii de Man) alimentados com dietas balanceadas contendo diferentes aglutinantes. Revista Brasileira de Zootecnia, v.26, n.4, p.638-644, 1997b.

SHIAU, S.Y. Utilization of carbohydrates in warmwater fish with particular reference to tilapia, Oreochromis niloticus $\mathrm{x}$ O. aureus. Aquaculture, v.151, p.79-96, 1997.

SILVA, D.J. Análise de alimentos (Métodos químicos e biológicos). Viçosa, MG: Universidade Federal de Viçosa, 1990. 166p.

SIPAÚBA-TAVARES, L.H.S. Limnologia aplicada à aqüicultura. Jaboticabal: Funep, 1995. 72p.

VIOLA, S.; ARIELI, Y. Evaluation of different grains as ingredients in complete feeds for carp and tilapia in intensive culture. Israel Journal Aquaculture, v.35, p.38-43, 1983.

VIOLA, S.; ARIELI, Y.; ZOHAR, G. Unusual feedstuffs (tapioca and lupin) as ingredients for carp and tilapia feeds in intensive culture. Israel Journal Aquaculture, v.40, n.1, p.29-34, 1988.

Recebido em: 24/05/01

Aceito em: 06/11/01 